\title{
Quality of health care of the medical units that provide services for Medical Insurance for a New Generation enrollees
}

\author{
Luis Durán-Arenas, PhD, (I) Vanessa Aldaz-Rodríguez, M en Admon de Serv de Sal, (2) \\ Luis Jasso-Gutiérrez, M en CM, (2) Samuel Flores-Huerta, M en CM,(2) \\ Luz del Carmen Hernández-Ramírez, M en C de Gestión y Pol de Sal, ${ }^{(2)}$ Juan Manuel Zurita, Act. ${ }^{(3)}$
}

\section{Durán-Arenas L, Aldaz-Rodríguez V, Jasso-Gutiérrez L, Flores-Huerta S, Hernández-Ramírez LC, Zurita JM. Quality of health care of the medical units that provide services for Medical Insurance for a New Generation enrollees. Salud Publica Mex 2012;54 suppl I:S42-S49.}

\begin{abstract}
Objective. In this evaluation we assess the quality of the general and clinical structure in medical units that deliver health services for the Medical Insurance for a New Generation (SMNG) enrollees. Materials and methods. The study population included 82 medical units that deliver health services to enrollees of the SMNG in 15 states of Mexico, during 2009. Two indexes: the general structure index and the clinical structure index were created. Results. It was found an unequal quality of the general and clinical structure in the different levels of care. The results suggest that the first level of care lacks both important general and clinical structural items. They also show on average a regular quality in the second level of care and a good quality in the third level of care medical units. Conclusions. Our results support the main conclusion of the work of Bulatao, "Improving services requires moving beyond policy reform to strengthening implementation of services".
\end{abstract}

Key words: quality of health care; quality evaluation; Mexico
Durán-Arenas L, Aldaz-Rodríguez V, Jasso-Gutiérrez L, Flores-Huerta S, Hernández-Ramírez LC, Zurita JM. La calidad de la atención en unidades médicas que proveen servicios para el Seguro Médico para una Nueva Generación. Salud Publica Mex 2012;54 supl 1:S42-S49.

\section{Resumen}

Objetivo. Se evalúa la calidad de la estructura física y clínica en las unidades médicas que proveen servicios de salud a los afiliados al Seguro Médico para una Nueva Generación (SMNG). Materiales y métodos. La población de estudio incluyó 82 unidades médicas de los tres niveles de atención del SMNG en 15 estados de México, en 2009. Se elaboraron dos índices: el índice de estructura general y el índice de estructura clínica. Resultados. Se encontró calidad variable en las unidades médicas. Los resultados sugieren que el primer nivel de atención tiene deficiencias en la estructura general y la estructura clínica. También se muestra una calidad regular en unidades de segundo y la mayor calidad en las de tercer nivel. Conclusiones. nuestros resultados están en armonía con la conclusión de Bulatao: "la mejora de los servicios requiere moverse más allá de la reforma de las políticas, hacia la implementación de una estrategia de fortalecimiento de los servicios".

Palabras clave: calidad de la atención a la salud; evaluación de calidad; México

(I) Facultad de Medicina, Universidad Nacional Autónoma de México. México.

(2) Hospital Infantil de México. México.

(3) Instituto Nacional de Salud Pública. México.

Received on: June I, 201I - Accepted on: January 3, 2012

Corresponding author: Dr. Luis Durán Arenas. Facultad de Medicina, Universidad Nacional Autónoma de México. Av. Universidad 3000. 04510 Delegación Coyoacán. México, DF, México email: Iduran19@liceaga.facmed.unam.mx 


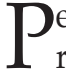
erformance assessment of healthcare services is receiving greater attention due to increasing health care expenditures, greater expectations among the population, and the need to obtain results from the invested resources. It has been documented in the international literature the need to consider the organizational characteristics of the health care system in order to assess the effects of programs or reforms. ${ }^{1,2}$ The experience in Colombia with the health reform of the 90's is very illustrative. According to Hsiao the main obstacle for the success of the reform was the structure of the Colombian Health Care System, including the management training of the health functionaries. ${ }^{3}$

Furthermore, a common limitation of the evaluations of health program interventions is that the evaluations tend to be focused on specific components of the program rather than on the organizational aspects that enable the medical units to deliver the health services. ${ }^{4,5}$ Therefore, a global evaluation of the potential for performance in terms of access and use cannot be realized. ${ }^{6}$

In this work we followed the original proposal of Donabedian about the approaches of evaluation of health care quality, in particular the need to link the structure, the process and the outcomes of health care. ${ }^{7}$ This is done this way because we are interested in assessing the quality attributes of health care according to the context of the health care system in Mexico; where a success in the increase in the financing mechanisms, make us turn to see the capacity to produce services and programs to assure an effective use of the budget. ${ }^{8}$ Then it is necessary to widen the scope of the evaluation, from an analysis of particular groups of patients, to the assessment of the structure and critical processes that include the work of health professionals, managers and even politicians. ${ }^{9}$

The structure and processes to be considered in the evaluation should take into consideration the following aspects:

Accessibility: understood as the ability of a patient to make use of services according to its rights and needs; Opportunity, the reception of health services at the time that the patient need it; Pertinent care: the performance or delivery of a service with effectiveness and reliability; Safety: control of the risk of accidents, adverse effects or iatrogenic effects; Continuity: to have the services needed according to the appropriate sequence of referral within the different levels of health care; Information: both the technical and administrative information needed by the user of health care services to comply to the treatment and appropriate delivery of services; Kindness: the courteous and respectful care of the health personnel with the patient and his her family. ${ }^{10}$
Finally, the evaluation of health services interventions needs to include a Health Impact Assessment. This is a methodology proposed by different authors, that served as the basis of the recommendations of the World Health Organization (WHO) to determine the impact on health of projects, policies and strategies that could have on effect on health. ${ }^{11,12}$ Health Impact Assessment is a multidisciplinary process that combines both qualitative and quantitative evidence in a decision-making frame. The WHO model:

\footnotetext{
"It is based on a model of health that includes the economic, political, social, psychological, and environmental determinants of health. If interventions with a real impact on the population's health require a comprehensive and structural approach, with Public Health measures taken at political level, those responsible for implementing such measures have to engage in the decision-making process and in the assessment of its effectiveness. To conduct Health Impact Assessment it is necessary to facilitate the integration of the existing data in order to perform the initial diagnosis and be able to investigate the late effects of the policy measures implemented" ${ }^{13}$
}

The objective of this study is to assess the quality of the medical structure in medical units that deliver health services for the Medical Insurance for a New Generation (Seguro Médico para una Nueva Generación, SMNG) enrollees. Following the experiences discussed in the previous paragraphs we have decided in the evaluation of the SMNG to assess the quality of the medical structure and critical processes in medical units that deliver health services for the SMNG enrollees. This analysis will be useful to identify the limitations, barriers and opportunities to improve the quality of health care and the effectiveness of the program. Currently, the added value of this project is that it identifies the extent to which the healthcare system is achieving its objectives and establishes a set of homogeneous indicators that could be used in the future.

\section{Materials and methods}

Study design. The methodology used in this study is based in the application of eight surveys in the sample of medical units selected. The surveys, were developed by the research team and the items explored were validated in a pilot study in medical units outside of the sample in Mexico City. The study protocol was registered and reviewed by the research and ethic commission of the Hospital Infantil de México Federico Gómez.

Sample design. The study population was all the medical units that deliver health services to enrollees of the 
Seguro Popular (Popular Health Insurance) in Mexico. A multiple stage sampling process was followed for the definition and selection of the medical units sample. First, the medical units were grouped according to the regions in Mexico (according to geographic, social development and economic criteria); in a second stage, within the regions, a sample of hospitals and ambulatory health care units that by norm have to have birth delivery services were randomly selected. Finally, within the medical units a census of medical providers was carried out in the morning shift, and medical charts were randomly selected for five tracers.

For the medical chart audits, the sample size was calculated according to the health care utilization rate per person and year taken from the Mexican National Health and Nutrition Survey 2006 (ENSANUT 2006). This was done for the five tracers and it was assumed that this rate was a good approximation to the use rate of SMNG enrollees.

In Table I are shown the medical units selected by level of care and state. A total of 82 medical units were selected, 29 at the first level of care, 30 at the second level and 23 at the third level of care in 15 states in the country, that were visited in 2009.

Measurement. The operationalization of the variables was based on the criteria and standards developed for the certification of medical units by the General Council of Health of Mexico. This is the standard in Mexico for the quality of the structure of medical units in different levels of care. They were modified to include the clinical structure in pediatric services.

General contents of the surveys:

1. Physical structure of the medical units according to first and second level of care.

2. Physical structure of the third level of care medical units (in particular neonatal intensive care units).

3. Health professional characteristics in first and second level of care medical units. This questionnaire was oriented to evaluate the qualifications, training and sufficiency of the human resources for health care.

Table I

LIST OF THE MEDICAL UNITS SELECTED, BY STATE

\begin{tabular}{|c|c|c|c|c|c|}
\hline State & $\begin{array}{c}\text { Total of } \\
\text { Medical Units }\end{array}$ & $\begin{array}{c}\text { Medical Units by } \\
\text { level of care }\end{array}$ & State & $\begin{array}{c}\text { Total of } \\
\text { Medical Units }\end{array}$ & $\begin{array}{l}\text { Medical Units by } \\
\text { level of care }\end{array}$ \\
\hline Campeche & 5 & $\begin{array}{l}\text { First level :2 } \\
\text { Second level: } 2 \\
\text { Third level: I }\end{array}$ & Michoacán & 4 & $\begin{array}{l}\text { First level:2 } \\
\text { Second level:2 }\end{array}$ \\
\hline Chihuahua & 4 & $\begin{array}{l}\text { First level: I } \\
\text { Second level: } 2 \\
\text { Third level: I }\end{array}$ & Querétaro & 5 & $\begin{array}{l}\text { First level:2 } \\
\text { Second level: } 2 \\
\text { Third level: I }\end{array}$ \\
\hline Coahuila & 5 & $\begin{array}{l}\text { First level:2 } \\
\text { Second level: } 2 \\
\text { Third level: I }\end{array}$ & Quintana Roo & 4 & $\begin{array}{l}\text { First level:2 } \\
\text { Second level: } 2\end{array}$ \\
\hline Distrito Federal & 15 & $\begin{array}{l}\text { First level: } 2 \\
\text { Second level: } 2 \\
\text { Third level: } 9\end{array}$ & San Luis Potosí & 5 & $\begin{array}{l}\text { First level:2 } \\
\text { Second level: } 2 \\
\text { Third level: I }\end{array}$ \\
\hline Guanajuato & 5 & $\begin{array}{l}\text { First level:2 } \\
\text { Second level: } 2 \\
\text { Third level: I }\end{array}$ & Tamaulipas & 5 & $\begin{array}{l}\text { First level:2 } \\
\text { Second level: } 2 \\
\text { Third level: I }\end{array}$ \\
\hline Hidalgo & 5 & $\begin{array}{l}\text { First level:2 } \\
\text { Second level: } 2 \\
\text { Third level: I }\end{array}$ & Tlaxcala & 5 & $\begin{array}{l}\text { First level:2 } \\
\text { Second level: } 2 \\
\text { Third level: I }\end{array}$ \\
\hline Jalisco & 5 & $\begin{array}{l}\text { Primer nivel :2 } \\
\text { Second level: } 2 \\
\text { Third level: I }\end{array}$ & Veracruz & 5 & $\begin{array}{l}\text { Second level: } 2 \\
\text { Third level: I }\end{array}$ \\
\hline Mexico & 5 & $\begin{array}{l}\text { First level:2 } \\
\text { Second level: } 2 \\
\text { Third level: I }\end{array}$ & General Total & 82 & $\begin{array}{l}\text { First level: } 29 \\
\text { Second level: } 30 \\
\text { Third level: } 23\end{array}$ \\
\hline
\end{tabular}


4. Health professional characteristics in third level of care medical units. This questionnaire was oriented to evaluate the qualifications, training and sufficiency of the human resources for health care, in particular in neonatal intensive care units.

5. Medical chart audits in first and second level of care medical units. This was done in four tracers:

5.1 Low birth weight: sufficiency of the health care structure; qualifications and training of the health care personnel; services delivered and its quality. 5.2 Congenital hypothyroidism screening: sufficiency of the health care structure; qualifications and training of the health care personnel; services delivered and its quality.

5.3 Iron supplementation for the prevention of anemia: sufficiency of the health care structure; qualifications and training of the health care personnel; services delivered and its quality.

5.4 Surveillance of child normal growth in children less than 2 years old: sufficiency of the health care structure; qualifications and training of the health care personnel; services delivered and its quality.

6. Medical chart audits in children with Respiratory Distress Syndrome in Neonatal Intensive Care Units: sufficiency of the health care structure; qualifications and training of the health care personnel; services delivered and its quality.

7. Enrollment process to Seguro Popular and financial resources flux in first and second level of care medical units.

8. Enrollment process to Seguro Popular and financial resources flux in third level of care medical units.

In this article are presented the results of the first two surveys. In order to present a better assessment of both the general structure and the clinical structure for health care, a data reduction process (normalized linear combination of items) was conducted in order to generate two indexes: the general structure index and the clinical structure index. These indexes were developed following a methodology presented by Contandriopoulos and his colleagues in the University of Montreal in Canada. ${ }^{14}$ The general structure index included items on the following aspects: access to the unit, reception, waiting room, ancillary services, administrative area, personnel dressing room, patient dressing room, clean room.

Analysis. Finally the indexes are presented as a goal-image of the general structure and the clinical structure elaborated following the approach used by Lamarche et al. ${ }^{15}$

This type of approach allows to describe in a radial graph the performance in different dimensions at the same time that allows the construction of a summary score of performance, as will be seen in the presentation of results.

\section{Results}

Before presenting the results it is important to remember that a premise of the sample design was to select medical units of first, second and third level of care that can produce birth delivery and children care services. To assure that the key identifier of the units (clues key) used was of those units that by normative standards could produce those services. The analysis is descriptive, the data is presented as percentages and since we are not making any claim of association nor analysis of factors associated with the quality of the structure no test of statistical significance is presented. It is important to realize that this is an example of evaluative research, our goal in this article is to describe the characteristics of the quality of the medical units surveyed, in other articles of this special number a series of different factors have been reviewed in a more analytical fashion.

\section{Evaluation of the first and second level of care medical units}

We found a considerable variation in the medical structure of the first and second level of care medical units. Even though by norm all the units should have the capacity to attend birth deliveries, among the second level units only $60 \%$ of them have the necessary structure for birth deliveries, whereas on the first level of care units, only five units out of 29 have birth delivery room. In all the units with birth delivery services there was a register of the births and 3\% of these units filled and deliver to the families the birth certificate at the time of discharge.

In relation to the credentials of the physicians, in the first level of care tend to be young and with less than five years of experience on average. Only $20 \%$ of these physicians had a family medicine specialty.

Most of the physicians at first and second level of care reported to have more than one job: $58 \%$ have clinical practice besides the medical unit where they were interviewed; if we consider only the second level physicians, $75 \%$ of them reported to have another job.

The physicians in both first and second level reported to assist rarely to continuous medical education activities and low knowledge of evidence based medicine that could be used in clinical decision making.

Even though $85 \%$ of the physicians reported the availability of clinical guides and protocols, only $60 \%$ of them reported to have access to protocols, $13.4 \%$ reported the use of protocols in their clinical practice. 
General Structure and Clinical Structure Indexes for first and second level of care medical units

The Clinical structure index is a combination of indexes for the following aspects of clinical care: physician office index, physical structure birth delivery room index, equipment birth delivery room index, nursing birth delivery room index.

Based on the General Structure Index all the first level of care medical units were classified in four groups: very good, good, bad and very bad structure. In table II is shown that 26 out of 29 first level of care units were classified with very bad structure, and the three remaining as bad. The second level of care units were classified in five groups: very good, good, regular, bad and very bad structure. In this case we found a better situation given that 18 of the units fell within the regular and very good categories, although only three were considered very good.

With regard to the Clinical Structure Index we classified the medical units in the same categories. In this case we found that $93 \%$ of the first level of care units fell under the categories of bad and very bad; whereas $20 \%$ of the medical care units of second level of care fell in the very bad and bad categories, and 30\% under very good category (table III).

Table II

General infrastructure indeX

Ist level
Very bad
26
Bad

3

\section{Good \\ 0}

\section{Very good}

Criteria

Access

Reception

Waiting room

Services

Administration

Dressing room

Health Personnel

Dressing room

Patients

Clean room

Access

Reception

Waiting room

Services

Administration

Dressing room

Health Personnel

Dressing room

Patients

Clean room

Table III

Clinical infrastructure indeX

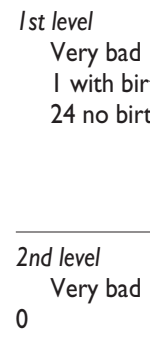

2nd level
Very bad
0

Bad
2
Bad 6
Good

$$
2
$$

Very good
Criteria

Physycian offices Birth delivery room Equipment in the Birth delivery room Nursing area in the Birth delivery room
Regular/ Good $4 / 10$

Very good
10

Physycian offices Birth delivery room Equipment in the Birth delivery room Nursing area in the Birth delivery room 
It is clear that the first level of care medical units studied had important structural limitations, both in the general and the clinical structure, this will certainly decrease the capacity to produce services financed by Seguro Popular, and also could be part of the reason why patients tend to go to the emergency departments of tertiary care hospitals.

In figures 1 and 2, we present some examples of medical units and the dimensions of both the general and clinical structure in first and second level of care. It is possible to see that almost all the aspects of general structure are lacking in the medical units of first level of care, in fact the units have only good access, and acceptable reception area and waiting room (figure 1); whereas in the clinical structure the major problems tend to be in the items that had to do with nursing structure and equipment. These results point to the deficiencies in both the physical structure and the staffing of these units, that are the major structural issues found.

In the second level of care units the major aspects lacking in the general structure are less homogeneous, in some units the major problem areas are related to support services, in others the administrative areas, only the physical access to the unit, reception and waiting room are scored as good in most of them; and in terms of the clinical structure the problems tend to be related to the nursing items (figure 2). In this case it can be seen that the general conditions of the units are better, however not uniform, there are important variations among the units as it is shown in figure 2 for the case of the clinical infrastructure index. This is a major issue given the importance of the nursing staff in the quality of health care, it does reflect the situation of the country with a big shortage in the supply of nurses.

\section{Evaluation of the third level of care medical units}

It is important to realize that the units of third level of care were selected with the criteria of high level of neonatal care (if they have Neonatal Intensive Care Units -NICU). Therefore, the sample included the best units in the states of Mexico for children care. We found that both the general and clinical structure of these units was satisfactory. In all the items, including equipment, physical structure, laboratory and main inputs for care these units were rated as good or very good. Nevertheless, there were some problems in the structure of health personnel, in particular $30 \%$ of the NICU did not have residents rotating through them.

In the 15 essential medical drugs for NICU care we found a good or very good supply and availability in the
With very bad

score
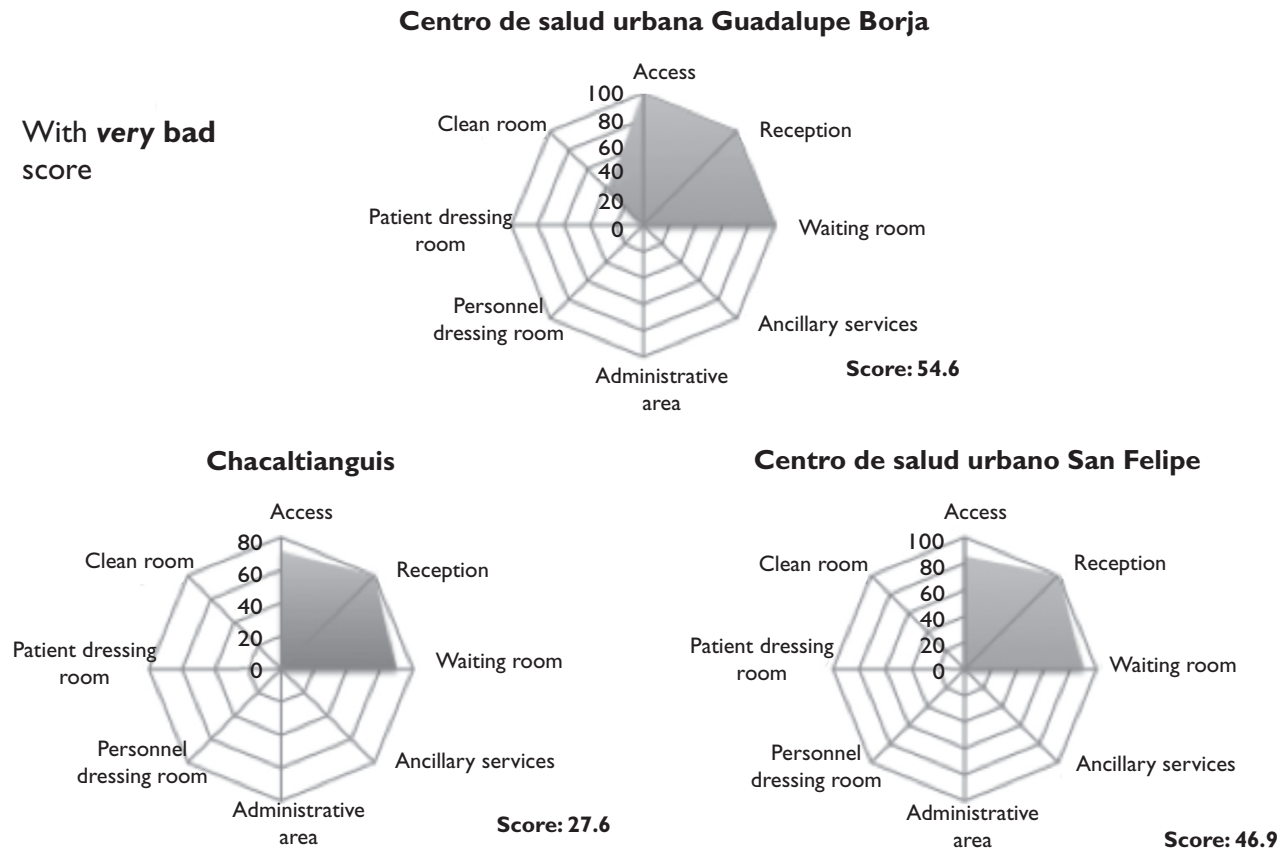

Mexico City. October 25th, 2009

Figure I. Examples of PRimary Care UNITS. General INFrastructure INDEX 


\section{Hospital General de Cozumel}

With bad score

Hospital General de Iztapalapa

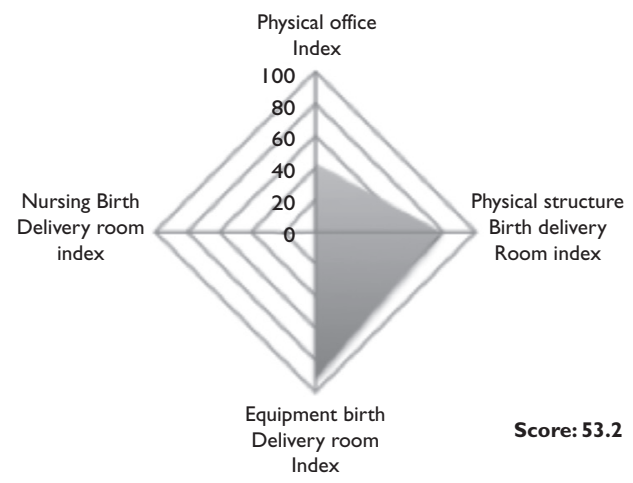

Physical office index

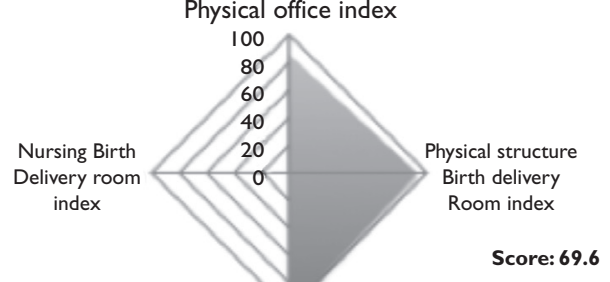

Equipment birth Delivery room Index
Hospital General Perote

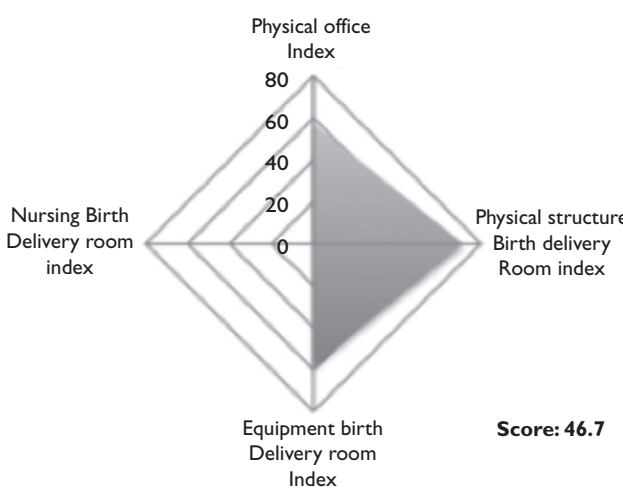

Mexico City. October $25^{\text {th }}, 2009$

\section{Figure 2. Examples of PRimary CARE Units. General infrastructure indeX}

units. Among them the availability of alveolar surfactant, the main medical drug for the distress respiratory syndrome, that was reported with good supply.

\section{Discussion and conclusions}

The most important finding in this study is the unequal quality of the general and clinical structure in the different levels of care. It is possible to observe that in all levels of care there are structural deficiencies; however, there is a gradient within the levels of care. The results suggest that the first level of care is the more limited, it lacks both important general and clinical structural items. This is a major concernas the first level of care is the access point to the system, if it does not have the structural requirements to provide good health care then the access to the system cannot be guaranteed. In an intermediate level of quality are situated the second level of care units, however still lacking important aspects, in particular the nurse staffing. Finally the best are third level of care medical units. This is a reflection of the investment decisions in the country, where most of the resources are devoted to hospitals and particu- larly high specialty care. However even here there are not enough residents and physicians to maintain the standards of NICU.

These differences by level of care suggest that the health services in the State Ministries of Health in the country are heterogeneous and have not developed appropriately the physical and clinical structure in their network of services. If the goal of universal care and coverage is to be accomplished, an important effort should be made to strengthen the structure of the state health services, in particular in particular the primary level of health care. As Medina and colleagues have advanced, "the contribution of primary care to population health and health systems organization has been well documented, but some authors have highlighted that in Third World countries it has gained more ground in discourse than in facts and practices, with different possible configurations", this variability may end up in quality differentials in health care. ${ }^{16}$

Our findings are also in agreement with the work of Medina and colleagues in Brazil where it was reported that in two case studies there were enough differences in primary health care organizational models to question 
whether the co-existence of the two modalities tends to gain stability, and to what extent such coexistence draws the real implementation of primary care closer to or farther from the goal-image of the Brazilian health reform.

These findings are in agreement also with other studies, for example, Bulatao and Ross reported that in a study conducted with the objective of rating maternal and neonatal health services in developing countries, ratings were particularly weak for emergency obstetric care in rural areas. ${ }^{17}$ What is important to realize is that we found these quality problems in mostly urban units, which are supposed to be the most complete in the states, in the case of Mexico the universal coverage of health care cannot be guaranteed unless an effort to strengthen primary level of health care infrastructure becomes a priority in the health system. Also our results support the main conclusion of the work of Bulatao, "Improving services requires moving beyond policy reform to strengthening implementation of services and to better staff training and health promotion. Increased financing is only part of the solution".

\section{Recommendations}

Finally a set of recommendations can be made to Seguro Popular:

- To establish a mechanism to follow up the allocation of resources for primary care services in the states. This to assure, that the medical units have the necessary resources to deliver the benefits package of Seguro Popular.

- To create incentives in order that the states invest in the improvement of the medical units general and clinical structure, both at the first and second level of care.

- To establish quality interventions, that go beyond the documentation of actions. This in order to assure an appropriate supervision of the quality of the services provided to SMNG enrollees.

- To establish training courses for health personnel in the priority programs of SMNG.

- To create incentives for the states to develop family medicine programs to reinforce the first level of care. This will help to make the physician profile to agree with the needs of primary care.

- To create incentives for the states, to train its health functionaries to improve the management of all levels of care in the state.
Declaration of conflict of interests: The authors declare that they have no conflict of interests.

\section{References}

I. Anderson JG. Health services utilization: framework and review. Health Serv Res 1973; fall:8(3) I84-199.

2. Campbell M, Fitzpatrick R, Haines A, Kinmonth AL., Sandercock P, Spiegelhalter $D$, et al. Framework for design and evaluation of complex interventions to improve health. BMJ 2000;321:694-6.

3. Hsiao W. Why is a systemic view of health financing necessary? Health Affairs. 2007; 26(4): 950-961.

4. Gakidou E, Lozano R, González-Pier E, Abbott-Klafter J, Barofsky C, Bryson-Cahn D et al (2006). Assessing the effect of the 200I-06 Mexican health reform: an interim report card. The Lancet. 368;(9550): 1920-1935. 5. Gericke CA Kurowski C Ranson MK, Mills A. Intervention complexity -a conceptual framework to inform priority-setting in health. Bulletin of the World Health Organization 2005;83:285-293.

6. Scatena LM, Scatena-Yilla TC, Ruffino-Netto A, Lmen-Kristski IIIA, Ribeiro-Monteiro TM, Figueiredo-Yendramini SM, et al. Dificuldades de acesso a serviços de saúde para diagnóstico de tuberculose em municípios do Brasil. Rev Saúde Pública 2009;43(3):389-97.

7. Donabedian A. The Definition of Quality and Approaches to Its Assessment. Vol I. Explorations in Quality Assessment and Monitoring. Ann Arbor, MI: Health Administration Press; 1980.

8. Broemeling AM, Watson DE, Black C, Reis RJ. Measuring the performance of primary health care: existing capacity and future information needs. University of Bristish Columbia. Centre for Health Services and Policy Research, 2006.

9. Kerguelén, C. Calidad en Salud: ¿Qué es? Bogotá, Colombia: Centro de Gestión Hospitalaria, 2003.

10. Aday LA, Andersen R. A framework for the study of access to medical care. Health Serv Res 1974; Fall:208-220.

II. Dannenberg AL, Bhatia R, Cole BL, Dora C, Fielding JC, Kraft K, et al. Growing the field of health impact assessment in the United States: an agenda for research and practice. Am J Public Health. 2006;96(2):262-70. I2. Dannenberg AL, Bhatia R, Cole BL, Heaton S, Feldman J, Rutt CD, et al. Use of Health Impact Assessment in the U.S.: 27 Case Studies, 19992007. Am J Prev Med 2008;34(3):24I-256

13. Sandin-Vazquez M and Sarria-Santamera A. Health impact assessment: assessing the effectiveness of policies in population health. Rev. Esp. Salud Publica. 2008, vol.82, n.3, pp. 26I-272.

14. Contandriopoulos AP, Champagne F, Denis JL, Avargues MC. L'évaluation dans le domaine de la santé: concepts et méthodes. Rev Epidemiol Sante Publique 2000; 48:5I7-39.

15. Lamarche PA, Beaulieu MD, Pineault R, Contandriopoulos AP, Denis JL, Haggert J. Choices for change: the path for restructuring primary health care services in Canada. (accessed on 30/Jul/2008). Available: http://www.chsrf.ca/final_research/commissioned_research/policy_synthesis/pdf/choices_for_change_e.pdf.

16. Medina MG, de Araújo Hartz ZM. The role of the Family Health Program in the organization of primary care in municipal health systems. Cad. Saúde Pública. 2009; 25(5): I I53-I I 67.

17. Bulatao RA, Ross JA. Rating maternal and neonatal health services in developing countries. Bull World Health Organ. 2002; 80 (9): 72I-727. 